\title{
A Review of Cost Measures for the Economic Impact of Domestic Violence
}

TRAUMA, VIOLENCE, \& ABUSE $000(00) \mathrm{I}-15$

(C) The Author(s) 2010

Reprints and permission:

sagepub.com/journalsPermissions.nav DOI: $|0.1177 /| 52483801037437 \mid$

http://tva.sagepub.com

@SAGE

\author{
Ko Ling Chan', and Esther Yin-Nei Cho
}

\begin{abstract}
Although economic analyses of domestic violence typically guide decisions concerning resource allocation, allowing policy makers to make better informed decisions on how to prioritize and allocate scarce resources, the methods adopted to calculate domestic violence costs have varied widely from study to study. In particular, only a few studies have reviewed the cost measures of the economic impact of domestic violence. This article reviews and compares these measures by covering approaches to categorizing costs, the cost components, and ways to estimate them and recommends an integrated framework that brings the various approaches together. Some issues still need to be addressed when further developing measures such as including omitted but significant measures and expanding the time horizons of others. The implications for future study of domestic violence costs are discussed.
\end{abstract}

\section{Keywords}

domestic violence, economic analysis, cost measures

Domestic violence, or more specifically violence against women, became a public issue during the second wave of the feminist movement. Since then, the physical and psychological impact of violence against women has been well documented. But not until the late 1980s did researchers begin focusing on the economic costs of this type of violence (Yodanis, Godenzi, \& Stanko, 2000). Doing so is important for several reasons. First, it helps to demonstrate the impact of domestic violence on society by expressing it in terms of a dollar value, thereby providing an unsophisticated way for policy makers and the general public to assess the problem by asking, are we paying a steep price for it? Second, because evidence-based policy making is gaining momentum, expressing a social problem such as domestic violence, in economic terms may help integrate policies into mainline policy analysis and priorities (Walby, 2004). Cost information can serve as a justification for spending resources to reduce the problem, while providing clues to the potential benefits or savings that might be achieved by preventing the problem in the first place. Third, focusing on costs helps to demonstrate the benefits or costs of intervention programs (Haddix, Teutsch, \& Corso, 2003; Teutsch, 1992), which in turn could improve resource allocation (National Center for Injury Prevention and Control [NCIPC], 2003). Because economic analyses of interventions help guide decisions on how to allocate resources, policy makers can make better informed decisions on how to prioritize and allocate scarce resources based on cost information. Finally, cost information is essential to both the follow-up appraisal and evaluation of a policy that must take place so that its costs and benefits can be weighed (Brand \& Price, 2000). Whereas a policy appraisal focuses on which policy proposal alternative offers the best value, policy evaluation concerns the value of a policy's benefits.

Since the late 1980s, a growing body of literature has examined the economic costs of domestic violence in different countries (Waters, Hyder, \& Rajkotia, 2004). The findings, however, have been inconsistent, even after adjusting for different currencies and cost values in different years. A review that converted findings for different countries into 2001 U.S. dollars (Waters et al., 2004) found the costs of intimate partner violence (IPV) to range from $\$ 717,000$ annually for $\mathrm{New}$ Zealand to $\$ 12.6$ billion for the United States. On a per capita basis, this breaks down to $\$ 0.17$ per individual in New Zealand based on a population of 4.3 million, compared with $\$ 41.00$ per individual in the United States based on a population of 304 million. However, it should be noted that the New Zealand study included only medical, welfare, legal, and police costs, whereas the U.S. study also included lost earnings, the opportunity cost of time, and loss of employment and worker productivity. Results among studies within a country have also been

\footnotetext{
' Department of Social Work and Social Administration, University of Hong Kong, Hong Kong SAR, China

${ }^{2}$ Department of Social Work, Hong Kong Baptist University, Hong Kong SAR, China
}

\section{Corresponding Author:}

Ko Ling Chan, Department of Social Work and Social Administration, The University of Hong Kong, Pokfulam Road, Hong Kong SAR, China

Email: eklchan@hku.hk 
inconsistent. In Canada, one study estimated overall costs, including medical costs, lost earnings, the opportunity cost of time, and psychological costs, at $\$ 1.2$ billion, whereas another study estimated medical costs alone to be $\$ 1.1$ billion; it is likely that the former figure is an underestimate (Yodanis et al., 2000).

This inconsistency in the findings of cost studies may be attributed to the different methods used to estimate costs, particularly in how they dictate what kinds of costs are to be included and how a certain cost component should be measured. Studies normally estimate direct expenditures such as medical costs, but intangible elements such as psychological costs are often excluded. Different studies may also measure the same cost components differently. Medical costs, for example, might be obtained from the reports of victims of violence or might simply be based on estimates from other sources. Such inconsistencies among studies obscure the whole picture of the economic impact of domestic violence, making it difficult to form a meaningful comparison across studies.

To enable further discussion on how better to capture the real and full economic impact of domestic violence, an understanding of the existing literature would be valuable as background; yet, no such review appears to have been done. We propose to fill this gap, therefore, by reviewing the cost measures of the economic impact of domestic violence in the existing literature. We examine the following questions: What kinds of costs do existing studies include? How are the costs measured across studies? What are the strengths and limitations of the various cost measurement approaches? What are the implications for future study? While we intend this article to provide background for further discussion, questions such as what should be measured or what is the best measure for each cost component lie beyond its scope.

\section{Method}

This review covers literature in the form of English language journal articles located in databases such as PsycINFO, sociological abstracts, social services abstracts, and MEDLINE. A search of keyword phrases such as partner violence, domestic violence, violence against women, and cost among abstracts up to 2009 produced 152 potential journal articles. We had two major criteria for articles to be included in this review. First, the study had to focus on partner violence, and second, it had to be an empirical study of economic costs. Because we were seeking to examine the kinds of costs included and how they were actually measured, we selected studies that explicitly discussed how each cost component was calculated, while rejecting those that presented mainly economic figures. In the end, we selected six articles from the potential pool that met the inclusion criteria. We also included another six research reports from various government agencies and research institutions that studied the costs of domestic violence or violence-related crime. Finally, we incorporated two additional studies on crime costs that were related to violence, because the cost measures they used were relevant to the study of domestic violence. The final sample size for the cost measures review was 14 studies. Because our focus was on cost measures, we did not present the findings of these studies. Matters such as the detailed technical or mathematical derivations behind some measures also lay beyond this article's scope. In short, we focused on reviewing which costs these studies examined and how they measured each cost component.

\section{Results}

\section{Inclusion of Costs-Cost Categorization}

The literature review showed that researchers tended to classify costs into categories, either explicitly or implicitly, when studying the economic costs of domestic violence. We found different approaches being taken to categorize costs depending on their dimensions. For instance, did a cost have a price in the market? Was it an actual expense directly related to the problem? Was this expense a result of or a response to the problem? Was it paid in the short term or over a longer period of time? And who paid for it?

We found a few inconsistencies in these studies in how they classified costs. First, some studies adopted what Walker (2003) called an ad hoc method. Although these studies grouped costs into categories, they provided no clear definition of what constituted a category. Second, some studies categorized costs into groups and made distinctions between categories, yet the categories used or the costs allocated to each one differed across studies, making comparisons between them somewhat complicated. Third, certain studies did not differentiate costs at all but simply presented the cost components separately. To handle these inconsistencies, we have created a framework that brings together the various approaches to cost categorization in the reviewed studies by providing a summary of the types of costs while defining their nature. However, before presenting such a summary, we first discuss the definitions used by the different approaches in the existing studies to categorize costs and their related cost components.

Tangible costs versus intangible costs. Tangible costs refer to costs that can be valued, sometimes imperfectly, in the market place (Collins \& Lapsley, 2003). Any reduction of these costs yields resources that then become available to the community for consumption or other uses. In domestic violence studies, tangible costs have usually included components such as medical care, mental health care, property damage and loss, the use of social and legal services, and productivity losses. Loss of consumption efficiency and government transfers also belong to this category. Intangible costs, however, refer to costs that cannot be readily valued in the marketplace and that can only be measured indirectly (Collins \& Lapsley, 2003). Such cost components include pain and suffering and lost quality of life owing to fatal or nonfatal injuries. Other intangible costs related to a work setting include damage to the image of an organization, decreased motivation and morale, diminished loyalty to the organization, lower levels of creativity, or an 
environment that is less conducive to work (Krug, Dahlberg, Mercy, Zwi, \& Lozaro, 2002). Another pair of terms close to the definitions of tangible and intangible costs are economic and noneconomic costs, the former referring to the loss of goods and services that have a price in the market, and the latter to the human and emotional costs to victims (Access Economics, 2004).

Direct costs versus indirect costs. Direct costs refer to actual expenditures that are directly related to producing goods or performing a service. In domestic violence, these are the costs of materials and labor that go into implementing a service as a result of violent incidents (Schwalberg, Gavin, \& Scarato, 1998). A similar definition adopted by the World Health Organization (WHO) is that direct costs are those arising from acts of domestic violence or interventions to prevent them, including the costs of medical and legal services, social services, refuge and housing, and the penal system (Krug et al., 2002). Cost components include medical care, mental health care, property damage and loss, and use of social and legal services. Indirect costs are costs that flow from domestic violence but do not directly relate to the incidents or the intervention. They include productivity losses, loss of consumption efficiency, and government transfers, as well as the long-term effects of violence on the victims and perpetrators, such as loss of wages and psychological costs, which are referred to as the costs of pain and suffering (Waters et al., 2004).

Cost as a consequence versus cost as a response. Brand and Price (2000) divided the costs of crime into anticipation, consequence, and response. With the exception of anticipation costs, which refer to defensive expenditure, these types of cost also apply to domestic violence. Costs as a consequence of domestic violence include components of medical care, mental health care, property damage and loss, productivity losses, lost consumption efficiency, government transfers, pain and suffering, and lost quality of life. Costs as a response to domestic violence refer to the use of social and legal services.

The payer: Individual versus government/community versus third parties. Using an accounting perspective in cost-benefit analysis, we can also categorize costs by deciding which perspective to adopt in calculating them (Rossi, Freeman, \& Lipsey, 1999). In other words, we can categorize costs by who has to bear them: individuals (victims or perpetrators), the government or the community, or third parties (e.g., employers, insurance companies, friends, or family; Brand \& Price, 2000; Greaves, Hankivsky, \& Kingston-Riechers, 1995). Each specific cost might be shared by different payers. Medical and mental health care costs can be borne by individuals, health insurance companies, the government, or even friends and family. Productivity losses are borne by both individuals and third parties (employers). The government and the community pay for the costs of services and transfers of payment, whereas individuals bear the human and emotional costs.
Short-term versus long-term costs. Costs can also be either short term or long term. Short-term costs relate to particular episodes of domestic violence and are normally incurred in the same year, such as costs related to short-term disruptions to health or work. Long-term costs occur over a longer period stemming from a history of domestic violence, such as the cumulative effects on health and productive capacity (Access Economics, 2004). Each type of cost, however, is likely to have both short- and long-term aspects.

\section{An Integration: Cross-Categorization of Costs}

Whereas the literature is diverse in its approaches to categorization, an integrated framework that brings together the various approaches would offer an overview and comparison of the cost components. Because certain approaches appear to overlap, such a framework would allow simultaneous multiple categorizations of a cost component, which would better capture its true nature. Table 1 displays the cross-categorization of costs; this shows that certain cost components can belong to different overlapping categories of costs. Tangible and intangible costs match with economic and noneconomic costs, respectively. The direct/indirect and tangible/intangible categories somewhat overlap each other and produce three sets of cross categories. Within each of the cross categories, it is further possible to distinguish cost as a consequence and cost as a response. Each cost component is also likely to have both shortand long-term aspects. For instance, the psychological harm of domestic violence could be long lasting and victims may need mental health care over a long period. But probably because data are limited, most of the cost components have been estimated as being relatively short-term; only those estimated to have long-term effects are included in the table. Likewise, each kind of cost could be borne by different parties, but the table includes only those parties that bear most of the costs and that the literature has discussed.

As Table 1 shows, the cost components fall into nine categories: medical care, mental health care, property damage and loss, productivity losses, loss of consumption efficiency, government transfers, use of services, pain and suffering, and lost quality of life. The empty cells in the table indicate that no cost components were identified as belonging to the respective cross categories.

\section{Cost Measures}

Medical care. Medical care generally includes emergency care, medical transport, physician care, overnight hospital stays, outpatient care, physical therapy, rehabilitation, dental care, and prescriptions. Smaller items such as medical devices, coroner costs, and related insurance claims processing are sometimes included. Table 2 lists the cost measures for medical care included in some studies.

The basic measure used in most studies followed the bottom-up approach, which refers to measuring all resources consumed by individuals and then calculating the unit cost for 


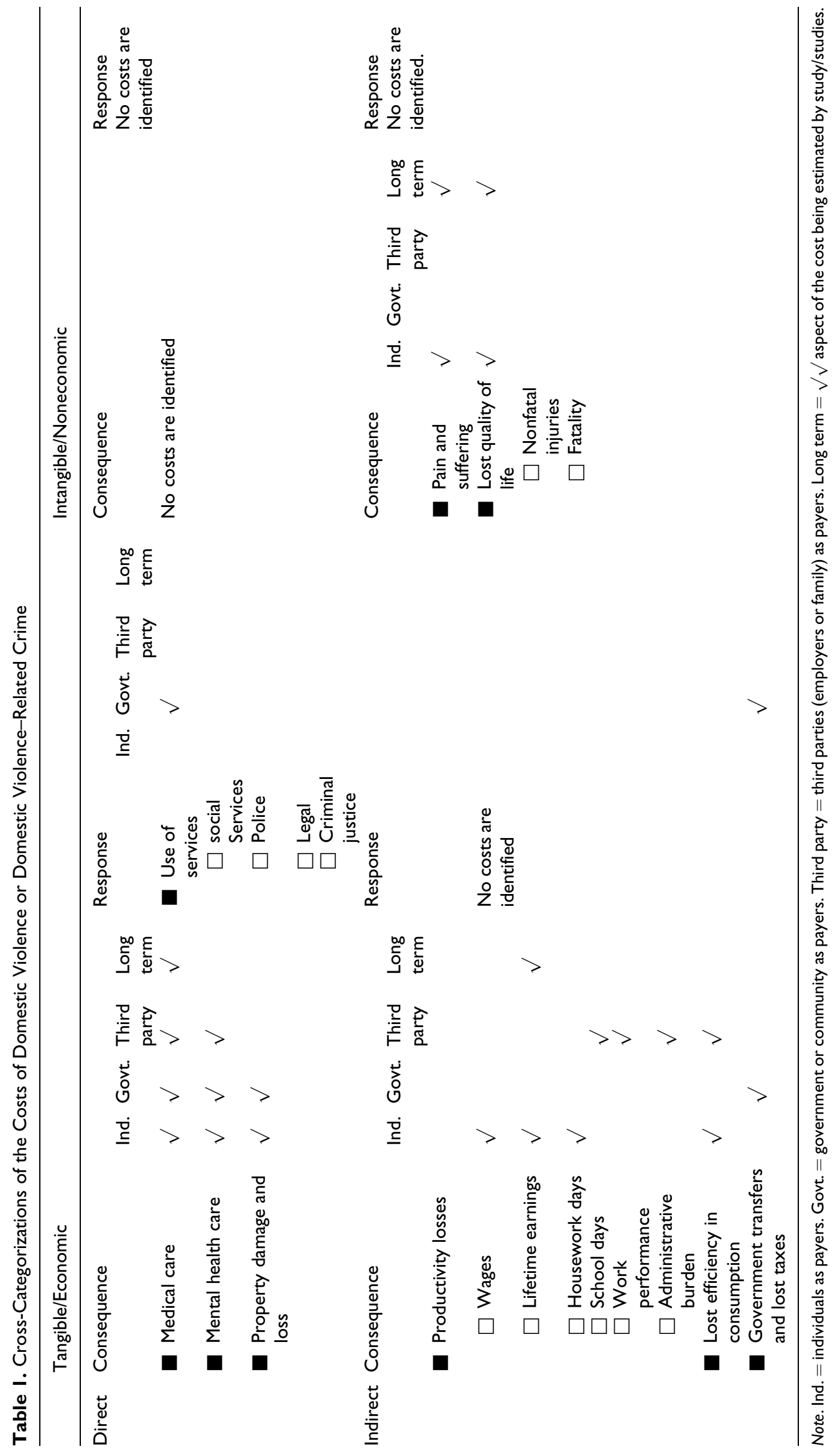




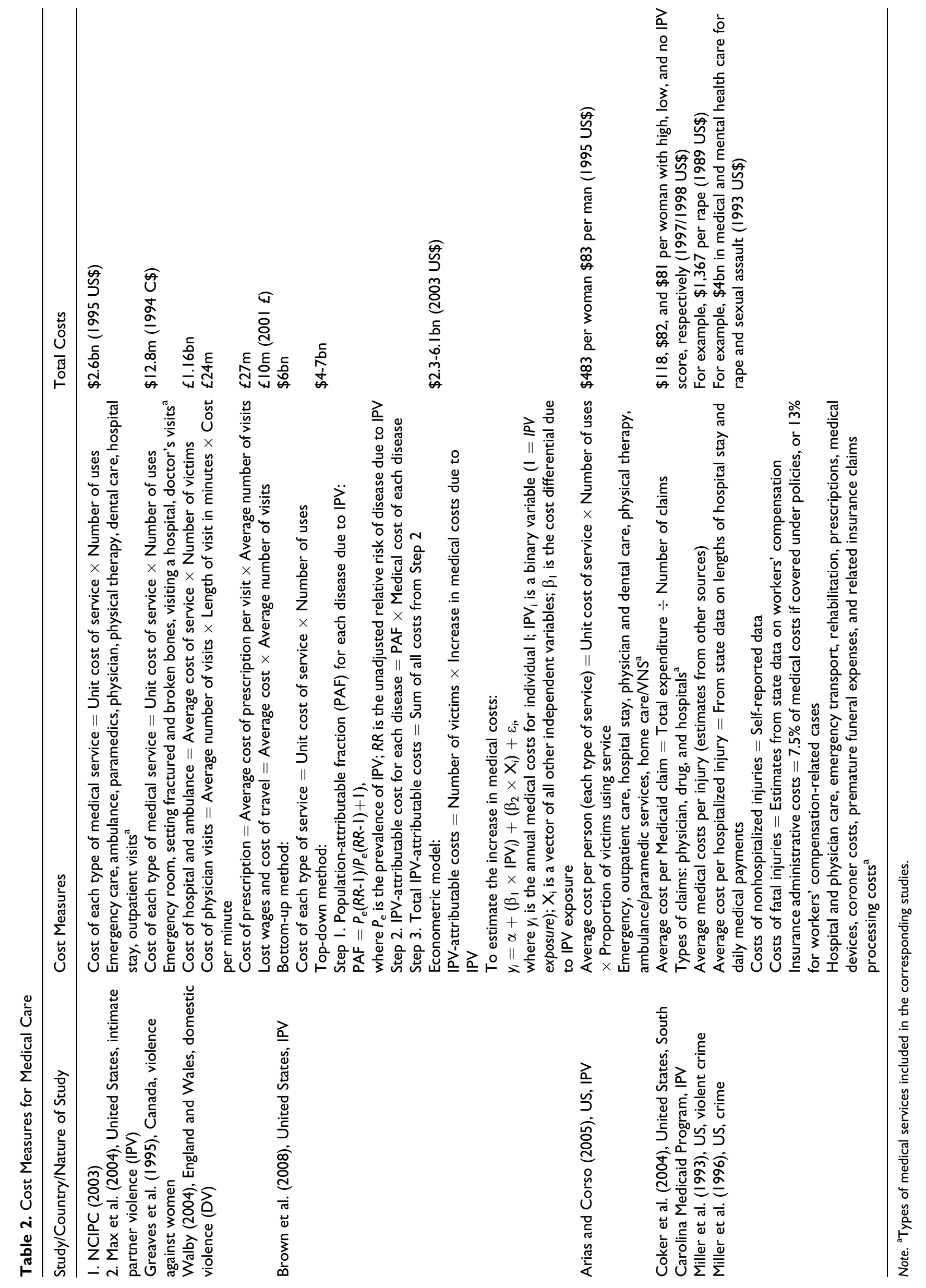


Table 3. Cost Measures for Mental Health Care

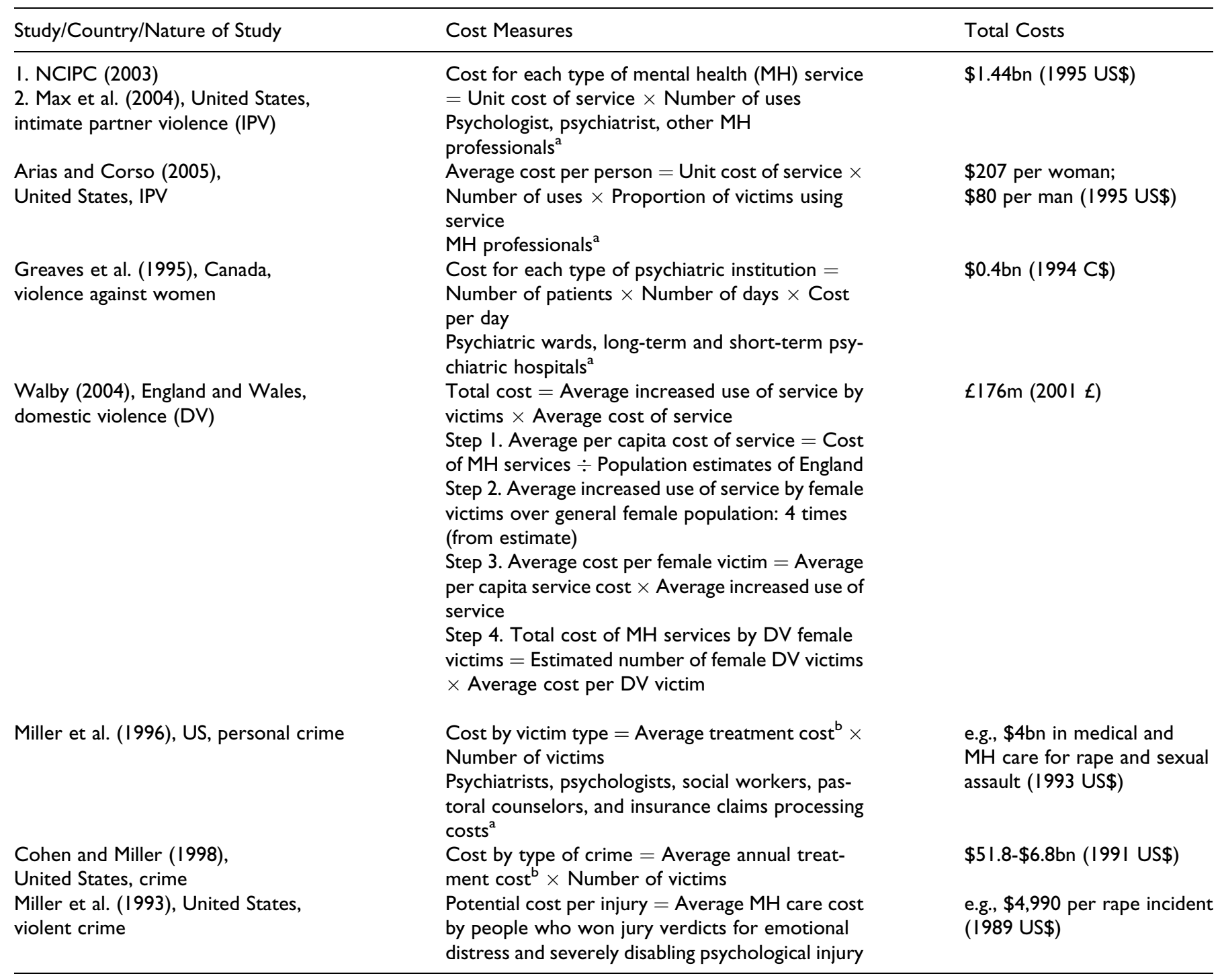

Note. ${ }^{a}$ Mental health care services included in the corresponding studies. ${ }^{b}$ Estimates of treatment costs from survey on mental health professionals.

each type of resource consumed (Mugford, Hutton, \& Fox-Rushby, 1998). First, the number of cases in each category of resource or service and the average cost for that category are derived and then multiplied together, generating the total cost (Access Economics, 2004). In other words, one begins with the smaller details and works up to the higher levels of cost. In the case of medical care, the unit cost of service is multiplied by the number of uses or victims for each type of medical service (Arias \& Corso, 2005; Control, 2003; Greaves et al., 1995; Miller, Cohen, \& Rossman, 1993; NCIPC, 2003; Walby, 2004). The total cost of medical care is obtained by adding up the total costs of each type of service. Different studies may use different unit service cost estimates from different sources.

Brown, Finkelstein, and Mercy (2008), however, used both a top-down and an econometric approach to estimate medical costs. The top-down approach usually starts from the total resource cost for a number of individuals and then calculates the unit cost per individual by dividing the total cost by the volume of services provided (Mugford et al., 1998). It begins at the highest level of cost, such as total costs, and works down to a smaller cost unit. Brown et al. used this approach to estimate the cost of the share of disease or health outcomes that is attributed to IPV. Starting from the total medical costs for each disease known to result from IPV, they determined the cost attributable specifically to IPV for each one. In such an approach, a separate population-attributable fraction (PAF) for each disease - that is, the share of disease that is attributable to IPV - is first computed. The IPV-attributable cost for each disease of interest is then estimated by multiplying each PAF by the corresponding medical cost. Total attributable costs to IPV are thus calculated as the sum of the IPV-attributable costs across all diseases. With the econometric approach, the IPVattributable costs are the product of the number of victims and the resulting increase in annual medical costs attributable to 
Table 4. Cost Measures for Property Damage and Loss

\begin{tabular}{lll}
\hline Study/Country/Nature of study & Cost Measures & Total Costs \\
\hline $\begin{array}{l}\text { Access Economics (2004), Australia, } \\
\text { domestic violence }\end{array}$ & Total cost $=$ Cost estimate per victim $\times$ Estimated number of victims & $\$ 243.7 \mathrm{~m}(2002-2003$ A $\$)$ \\
$\begin{array}{l}\text { Miller et al. (1996), United States, } \\
\text { personal crime }\end{array}$ & $\begin{array}{l}\text { Cost of loss }=\text { Values of property damage and loss + Insurance claims } \\
\text { processing costs (16\% of insured losses) }\end{array}$ & $\begin{array}{l}\text { For example, } \$ 750 \text { per } \\
\text { robbery victim }\end{array}$ \\
\hline
\end{tabular}

IPV. The increase in annual medical costs is estimated by a regression model that analyzes data on medical expenditures and the IPV exposure of individuals (Jones et al., 2006; Ulrich et al., 2003; Wisner, Gilmer, Saltzman, \& Zink, 1999).

We found the findings from studies that adopted the three approaches all to be plausible; we could detect no evidence of bias or a clear gold standard among them (Brownet al., 2008), although some potential limitations have yet to be addressed when following these approaches. The bottom-up or unit cost approach relies heavily on the use of cost estimates from other sources. These cost estimates, however, could be inaccurate if the sources are old or come from small and nonrepresentative samples. One possible drawback of the topdown method, however, is that the PAF formula could suffer from a confounding effect or effect modification (Brown et al., 2008). Although estimating the incremental cost with an econometric model is straightforward if data are available, the results could be problematic if the issue of confounding variables like IPV in the estimation model is not addressed (Brown et al., 2008). Therefore, even though the cost measures used by the three approaches seem to be equally useful for estimating costs, caution should be exercised when adopting them because of their possible limitations.

Mental health care. Mental health care consists of services to victims by psychiatrists, psychologists, pastoral counselors, marriage and family counselors, and social workers; Table 3 presents the related cost measures.

The most common measure followed the bottom-up method - the unit service cost multiplied by the number of uses, or the average treatment cost times the number of victims (Arias \& Corso, 2005; Control, 2003; Greaves et al., 1995; Miller, Cohen, \& Wiersema, 1996; NCIPC, 2003). Walby (2004), however, took a different approach to obtaining total costs by first estimating the general increased use of mental health services by victims of domestic violence and then multiplying this by the average cost of mental health services. Miller et al. (1993), however, equated the potential mental health costs per psychological injury to the average mental health costs incurred by people who had won jury verdicts for emotional distress and severely disabling psychological injury. However, it is preferable to use the unit cost and econometric methods, if data are available, because these methods are more straightforward and relatively accurate.

Property damage and loss. Although measuring the costs of property damage and loss would be straightforward, few such estimations have been made (Table 4), probably owing to a lack of data. One study acquired estimates of property loss per victim from other sources (Access Economics, 2004), while another also added the costs of insurance claims processing (16\% of insured losses) to the reported value of property loss to obtain the total value of loss (Miller et al., 1996).

Productivity losses. Productivity losses comprise costs incurred by lost wages, lost lifetime earnings, increased costs for work organizations, lost housework, and lost school days. Table 5 shows the cost measures for productivity losses.

Lost wages are measured by the average wage rate multiplied by the average amount of time absent from work (Arias \& Corso, 2005; Brand \& Price, 2000; Miller et al., 1993; NCIPC, 2003). Lost lifetime earnings for premature death are measured by the present value of lifetime earnings (PVLE; Greaves et al., 1995; Miller et al., 1996; NCIPC, 2003). Estimates of the expected earnings lost over the years are often based on an individual's age at death, sex, average annual earnings, labor force participation rate, and expected retirement age. The basic idea behind PVLE is that the expected lifetime earnings of an individual - the total value that the person is expected to earn over his or her remaining work life-is expressed in the present dollar value. That is, anticipated future earnings are discounted by taking into account risks, inflation, positive time preference, and expected productivity gains (Access Economics, 2004). A discount rate of 3\%-5\% is generally used (Greaves et al., 1995; Schwalberg et al., 1998). The value to be discounted after a number of years can be expressed as follows: Discounted value $=$ value $/(1+r)^{t}$, where $t$ is the number of years from now and $r$ is the discount rate.

The increased costs borne by employers as a result of domestic violence or other kinds of crime are usually the costs of managing absenteeism and hiring replacements (Access Economics, 2004). In one study, each day a victim or a perpetrator was absent from work was assumed to require $30 \mathrm{~min}$ to process the employee's absence and rearrange the work load (Access Economics, 2004). The associated measure was the total increased management time - number of days of absence times $0.5 \mathrm{hr}$ of management time - divided by the managers' weekly work hours and then multiplied by their weekly salary.

Reeves and O'Leary-Kelly (2007) developed better measures to estimate lost productivity stemming from reduced employee work performance, including absenteeism and tardiness. The annual absenteeism costs are determined by the number of work hours missed per month multiplied by the hourly salary and then by 12 (months). In measuring the cost of 


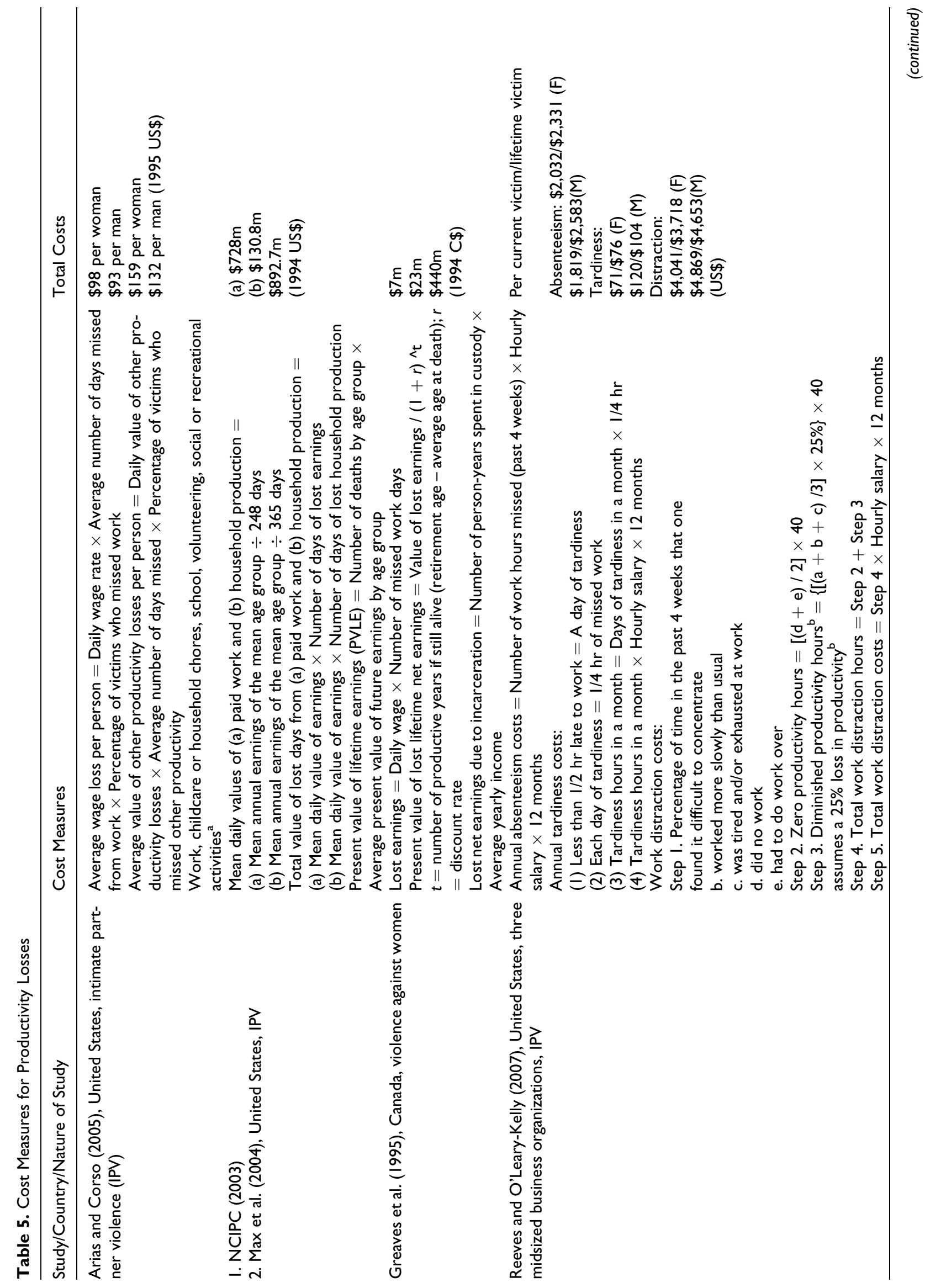




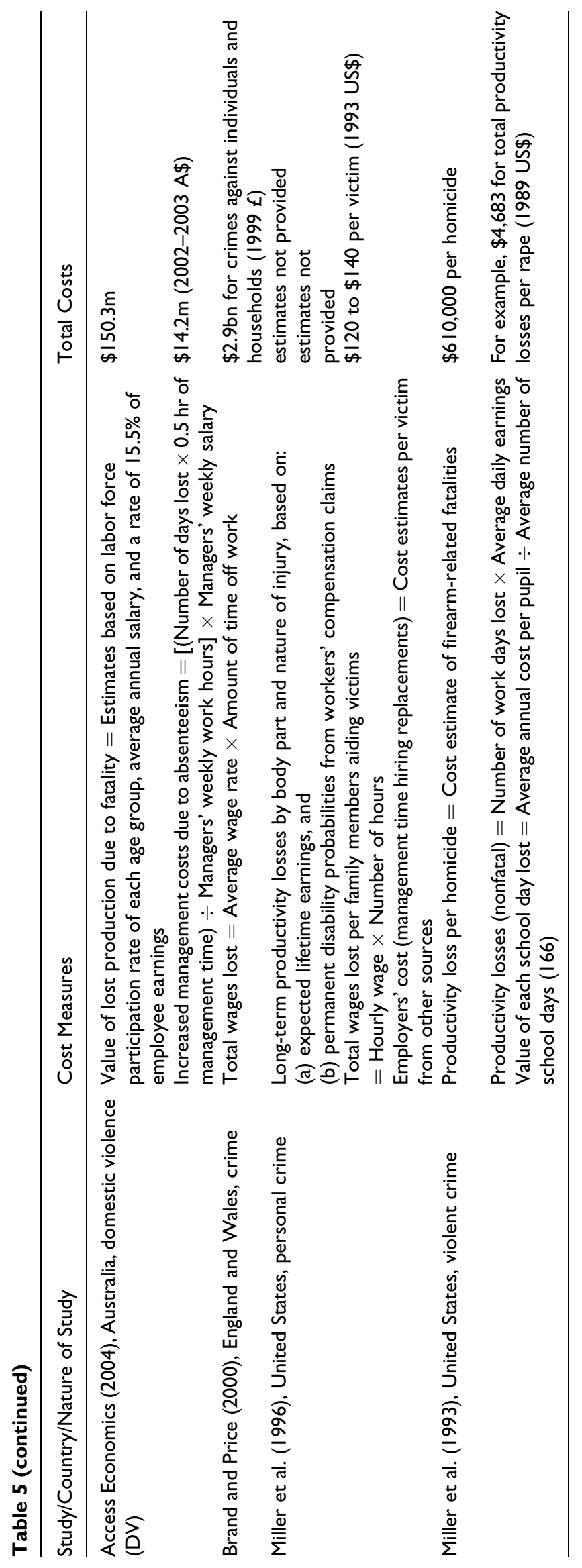


Table 6. Cost Measures for Loss of Consumption Efficiencies in the Household

\begin{tabular}{lll}
\hline Study/Country/Nature of Study & Cost Measures & Total Costs \\
\hline $\begin{array}{l}\text { Access Economics (2004), Australia, } \\
\text { domestic violence }\end{array}$ & $\begin{array}{l}\text { Step I. Equivalent disposable incomes (EDI) = Combined household income/ } \\
\text { (Number of household members) }\end{array}$ & $\begin{array}{l}\text { S2.3bn (2002-- } \\
\text { Step 2. Loss of standard of living = EDI not in relationship-EDI if in relationship }\end{array}$ \\
\hline
\end{tabular}

Table 7. Cost Measures for Government Transfers

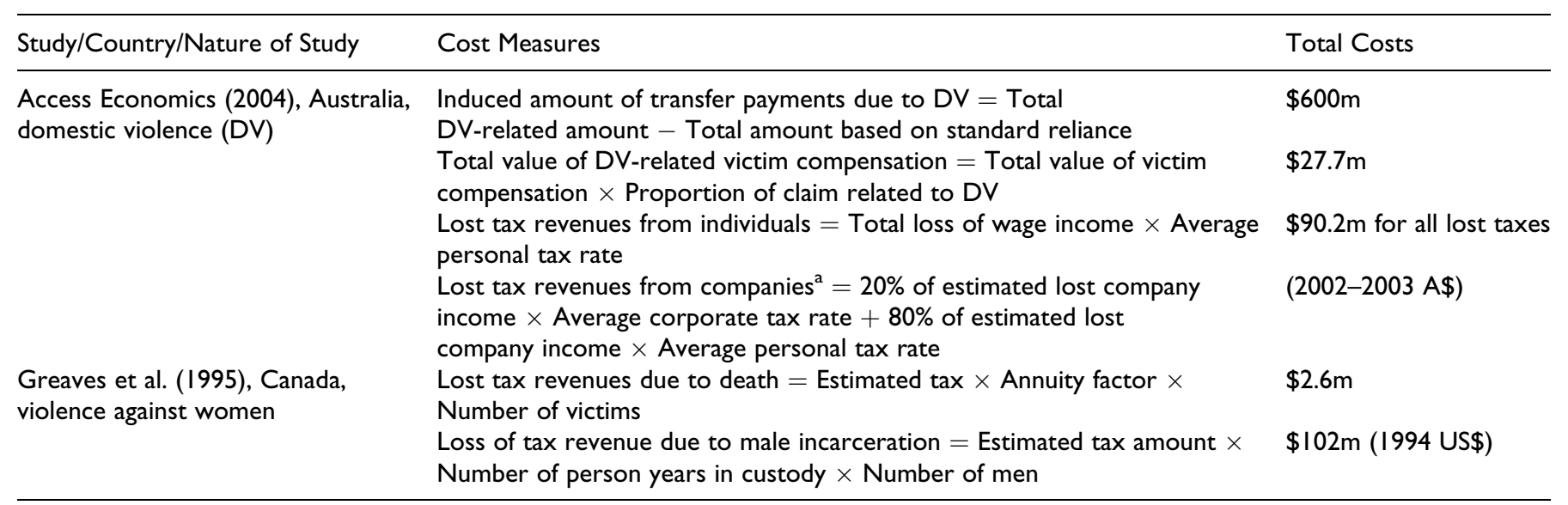

Note. ${ }^{\text {A Approximately }} 80 \%$ of company income, although taxed at $30 \%$, is distributed to domestic shareholders (as franked dividends), meaning that the $30 \%$ tax is rebated, with the income charged at the relevant personal tax rate in Australia (Access Economics, 2004).

tardiness, being less than half an hour late is considered tardy and each day of tardiness is counted as a quarter hour of missed work. The annual tardiness costs are the number of tardiness hours in a month multiplied by the hourly salary and then by 12 (months). Total work distraction time in a month includes both the time of zero productivity and the time of diminished productivity. The former is based on the average of the time that employees do no work and the time they have to do work over. The latter is based on $25 \%$ of the average of the total time that employees have difficulty concentrating, work more slowly than usual, and are tired or exhausted at work. The total work distraction costs then consist of the total monthly work distraction time multiplied by the hourly salary times 12 (months).

Loss of consumption efficiency in the household. It has been suggested that women who have experienced domestic violence in the past have a lower probability of being either married or in a de facto relationship (Access Economics, 2004). As they are less likely to be in relationships in the future, they may suffer from a loss of consumption efficiency in the household, which refers to the loss of household economies of scale. The basic idea is that the income needed for a household to reach a given standard of living rises in a less-than-proportional manner to the number of people living in a household (Access Economics, 2004).

The equivalent disposable income (EDI), which is calculated as the combined income of all household members divided by the square root of the number of persons in the household, can be used to reflect the household's standard of living. The loss of standard of living is thus measured by the difference between the EDI when people are no longer in a partnered relationship after domestic violence and the EDI that the same people would have had if they had remained partnered (Table 6). The difference in EDI seems to be an appropriate and useful measure for quantifying the loss of living standards resulting from domestic violence. Because this loss was excluded in most studies, future studies should seek to include it.

Government transfers. Loss of tax revenues and government benefits resulting from domestic violence are the costs borne by the government. Table 7 shows that lost tax revenues can be estimated based on information regarding estimated lost incomes, whether of the individual or the company, and the associated average personal or corporate tax rates (Access Economics, 2004). Similarly, multiplying the value of each transfer payment by the number of claims gives the total value of the transfer payments. Probably, owing to the lack of data, the receipt of government benefits by domestic violence victims has rarely been studied. Yet, findings suggest that a woman's experience of physical violence within the previous 3 years is associated with a $35 \%$ increase in the probability that she will receive some form of government benefits (Access Economics, 2004). Because of data constraints and difficulty separating out the cause-and-effect relationship between payment receipt and domestic violence, an "induced" additional transfer payment owing to domestic violence has been estimated instead (Access Economics, 2004; see Table 7). It is reasoned that the total payment amount would be the sum of the amount allotted to those victims who would ordinarily require support (standard 
reliance) and the amount allotted to those more likely to need it now because of domestic violence. The induced payment is thus the difference between the total amount of payments related to domestic violence and the estimated amount that the victims would ordinarily require based on the standard reliance rate.

The calculation for the loss of income tax from victims, perpetrators, and employers, as well as the additional induced transfer payments, becomes the extra tax dollars that now need to be collected (Access Economics, 2004). This is the deadweight loss of taxation, which results from payment, tax loss, or administration. In economic terms, deadweight loss is the loss of consumer or producer surplus resulting from imposing a distortion on the equilibrium level of output and prices (Access Economics, 2004; Weimer \& Vining, 1999). It means a loss of economic efficiency and represents lost value to citizens that government revenue does not capture.

Use of services. The costs of services include costs for policing, the criminal justice system, civil legal procedures, housing, and social services. As Table 8 shows, studies have adopted the bottom-up approach, by which they multiply unit cost measures by the number of victims or incidents to calculate total costs. The unit cost measures are sometimes estimates taken from other sources, such as when calculating police and emergency response costs (Miller et al., 1993; Miller et al., 1996), or are derived directly from the data, such as when calculating accommodation costs, criminal justice system costs, or legal costs (Access Economics, 2004; Greaves et al., 1995; Walby, 2004).

However, a top-down approach that starts from the total costs of a service could also be used, as Walby (2004) did to estimate criminal justice system and police costs. First, the costs per type of violent crime are extracted from the total cost data. The proportion of the domestic violence-related incidents for each type of crime is also taken out. Multiplying these proportions by the cost per type of violent crime then produces the total costs related to domestic violence. Thus, both a bottom-up and a top-down approach can be effective.

Pain, suffering, and lost quality of life. Studies have also used the willingness-to-pay (WTP) approach and jury awards to estimate the costs of pain, suffering, and lost quality of life. The WTP approach estimates pain, suffering, and lost quality of life from fatalities and nonfatal injuries, whereas the jury award method estimates mostly pain, suffering, and lost quality of life from nonfatal injuries (Brand \& Price, 2000; Clark, Biddle, \& Martin, 2002; Miller et al., 1993; Miller et al., 1996). In the economics literature, the WTP approach was developed to measure mortality and morbidity risk. The value of life or statistical life, which refers to the value of an unknown or statistical individual's life and not of any particular person's life, is estimated in terms of the amount people are willing to pay for safety to reduce risks to their life- such as smoke detectors and safer automobile features - or are willing to accept as compensation for increased risk (Access Economics, 2004; Brand \&
Price, 2000). Estimated values range from US\$500,000 to US\$7 million (Miller et al., 1996). Estimates of the cost of reduction in quality of life can also be based on compensation in court cases or the jury award method. WTP amounts generally equal an estimated $70 \%-80 \%$ of jury compensation amounts. If quality-adjusted life years (QALYs) are not available for some injuries, the value of lost quality of life is assumed to be $75 \%$ of jury compensation (Miller et al., 1993).

Some studies have taken the values of lost quality of life owing to fatalities from the estimated values of life given in sources based on the WTP technique (Clark et al., 2002; Miller et al., 1996; Walby, 2004), as shown in Table 9. Both the WTP method and the jury award data are used to estimate the costs of pain, suffering, and lost quality of life resulting from nonfatal injuries. In the WTP approach, pain, suffering, and lost quality of life are measured in terms of disability-adjusted life years (DALYs), where 0 represents a year of perfect health and 1 represents death (Access Economics, 2004). This is the converse of QALYs, where 1 represents perfect health. The number of healthy life years lost can be obtained by estimating the DALYs owing to domestic violence based on various sources of data. Before converting DALYs, or the number of healthy years lost, into a monetary value, the value of a life year (VLY) should be determined. As given in the Access Economics (2004) study (see Table 9), the VLY can be determined from the following equation: VSL $=\mathrm{SUM}\left[\mathrm{VLY} /(1+r)^{t}\right]$, where VSL is the ascribed value of a statistical life, $r$ is the discount rate, and $t$ is the number of years between the incident and the average life expectancy. The total value of pain, suffering, and lost quality of life then becomes the DALYs multiplied by the VLY.

In the jury award method, jury award data for compensating pain and suffering are modeled as a function of lost wages, medical expenses, victims' characteristics, and severity of injury (Clark et al., 2002; Miller et al., 1993; Miller et al., 1996). The results are then applied to the data from related studies to obtain the average jury award, which is calculated as the estimated value for pain and suffering.

Human and emotional costs have rarely been calculated in the literature on domestic violence. One reason is that developing an objective method to do the calculation is difficult (Walby, 2004); another is that people might feel uncomfortable putting a dollar value on human costs. Cohen and Miller (1998), however, argued that by not including human costs, we underestimate the scale of the impact of the crime and make inappropriate policy decisions. Including human costs in various policy domains is already part of the evidence-based policy-making process in the United Kingdom as well as several other countries (Walby, 2004). The WTP and jury award approaches, which are well developed and have been widely adopted in other policy areas, could be potentially useful methods to adopt in studies of domestic violence.

\section{Implications}

From this review of the cost measures regarding the economic impact of domestic violence, we are able to draw some 
Table 8. Cost Measures for Use of Services

\begin{tabular}{|c|c|c|}
\hline Study/Country/Nature of Study & Cost Measures & Total Costs \\
\hline \multirow[t]{4}{*}{$\begin{array}{l}\text { Walby (2004), England and } \\
\text { Wales, DV }\end{array}$} & $\begin{array}{l}\text { Criminal justice system (CJS) costs and police costs: } \\
\text { Step I. Obtain (a) total CJS and total police costs, and } \\
\text { (b) CJS costs and police costs per type of violent crime } \\
\text { Total CJS costs = CJS cost } \text { crimel }+ \text { CJS cost } \text { crime2 }_{\text {crime }}+\ldots \text { etc. } \\
\text { Total police costs = police cost }{ }_{\text {crimel }}+\text { police cost } \\
\text { crime2 } \\
+\ldots \text { etc. } \\
\text { Step } 2 \text {. Derive the proportion of violent incidents that are } \\
\text { DV-related in each type of violent crime: } \\
\text { DV\% crimel; DV\% crime2 etc. } \\
\text { Step 3. Apply DV proportion to the cost per crime and obtain } \\
\text { the total CJS and police costs that are DV related: }\end{array}$ & $f 1.02 \mathrm{bn}$ \\
\hline & $\begin{array}{l}\text { Total DV-related police costs }=(\text { police cost } \text { crimel } \times \text { DV\% crimel })+ \\
\left(\text { police cost } \text { crime } 2 \times D V \%_{\text {crime } 2}\right)+\ldots \text { etc. } \\
\text { Costs of social services for children }=(\text { Total costs of children } \\
\text { services } \times \% \text { of co-occurring cases of DV and children }) \div 2\end{array}$ & $\begin{array}{l}£ 70 \mathrm{~m} \\
£ 37 \mathrm{~m}\end{array}$ \\
\hline & $\begin{array}{l}\text { Housing costs of each accommodation type } \\
=\text { Expenditure } \times \% \text { of homeless households of DV }\end{array}$ & $\begin{array}{l}£ 3 \mid 2 \mathrm{~m} \\
(200 \mid £)\end{array}$ \\
\hline & $\begin{array}{l}\text { Total housing benefit }=(\text { Average benefit amount per week }) \times \\
\text { (Number of homeless households of DV }) \times(\text { Average length } \\
\text { of payment) } \\
\text { Cost for each type of civil legal proceedings }=\text { Number of } \\
\text { civil legal proceedings } \times \text { Average proceeding cost }\end{array}$ & \\
\hline \multirow[t]{2}{*}{$\begin{array}{l}\text { Miller et al. (1996), US, } \\
\text { personal crime }\end{array}$} & $\begin{array}{l}\text { Cost of police and emergency response }=\text { Estimate per } \\
\text { case from other source }\end{array}$ & $\$ 4 b n$ \\
\hline & $\begin{array}{l}\text { Cost of victim services = Estimate per victim or incidence } \\
\text { from other source }\end{array}$ & $\begin{array}{l}\text { For example, } \$ 1,800 \text { per } \\
\text { child abuse (1993 US\$) }\end{array}$ \\
\hline \multirow[t]{2}{*}{$\begin{array}{l}\text { Miller et al. (1993), } \\
\text { United States, violent crime }\end{array}$} & $\begin{array}{l}\text { Unit cost of police response = Based on salary, fringe benefits, } \\
\text { administrative overhead, average time on a case per crime category }\end{array}$ & Estimate not provided \\
\hline & $\begin{array}{l}\text { Average emergency transport costs for hospitalized nonfatal } \\
\text { injuries = Estimate of one-way transport from another source }\end{array}$ & $\$ 144$ (I989 US\$) \\
\hline $\begin{array}{l}\text { Brand and Price (2000), } \\
\text { England and Wales, crime }\end{array}$ & $\begin{array}{l}\text { Total police cost }=\text { Applied proportion of time spent on } \\
\text { crime-related tasks to the police budget }\end{array}$ & $\begin{array}{l}£ \mathrm{I}, 400 \text { per incident of } \\
\text { personal violence excluding homicide } \\
(1999 €)\end{array}$ \\
\hline
\end{tabular}

implications for future research. Specifically, those implications relating to the categorization of costs, the inclusion of cost components, the use of data, and the design of measures can be considered a guiding framework for those who intend to further discuss or study the topic. The issues that emerge from this framework would then be matters that researchers need to address.

\section{Categorizing and Defining Costs}

As the discussion on categorizing costs shows, the literature holds no consensus on how to classify or define costs. Different studies have defined costs in different ways, while some have provided no definition at all. Thus, we recommend that 
Table 9. Cost Measures for Pain, Suffering, and Lost Quality of Life

\begin{tabular}{|c|c|c|}
\hline \multicolumn{3}{|l|}{ Study/Country/Nature of Study } \\
\hline & Cost Measures & Total Costs \\
\hline $\begin{array}{l}\text { Access Economics (2004), } \\
\text { Australia, domestic violence } \\
\text { (DV) }\end{array}$ & $\begin{array}{l}\text { The value of pain, suffering, and premature death: } \\
\text { Step I. Derive the value of a life year }(V L Y) \text { after ascribing } \\
\text { a value to a statistical life }(V S L) \text { : } \\
\text { VSL = SUM }\left[V L Y /(I+r)^{t}\right] \\
r \text { is the discount rate; } t \text { is the number of years between the incident } \\
\text { and the average life expectancy } \\
\text { Step 2. Convert disability-adjusted life years (DALYs) to dollar terms } \\
\text { based on the VLY: Total costs = DALYs } \times \text { VLY }\end{array}$ & $\$ 3.5 b n(2002-2003 \mathrm{~A} \$)$ \\
\hline $\begin{array}{l}\text { Walby (2004), England and } \\
\text { Wales, DV }\end{array}$ & $\begin{array}{l}\text { Costs of pain, suffering, lost quality of life }(\mathrm{LQOL})=\text { Cost estimates } \\
\text { based on willingness-to-pay approach from other sources }\end{array}$ & $€ \mid 7 \mathrm{bn}(200 \mid \ell)$ \\
\hline \multirow[t]{2}{*}{$\begin{array}{l}\text { Clark et al. (2002), United } \\
\text { States, violence against women }\end{array}$} & Lost quality of life (fatal): Cost estimate from Miller et al. (1996) & $\$ 2.2 \mathrm{~m}$ per fatal crime \\
\hline & $\begin{array}{l}\text { Jury award for pain, suffering, and lost quality of life (nonfatal) }= \\
\text { Function (lost wages, medical costs, victim characteristics, injury } \\
\text { severity) }\end{array}$ & $\begin{array}{l}\$ 22,000 \text { per nonfatal assault ( } 1998 \\
\text { US\$) }\end{array}$ \\
\hline $\begin{array}{l}\text { Miller et al. (1993), United } \\
\text { States, violent crime }\end{array}$ & $\begin{array}{l}\text { Jury award for pain and suffering = Function (medical care costs, } \\
\text { productivity costs, category of injuries) } \\
\text { Lost quality of life (nonfatal injuries) = quality-adjusted life years } \\
\text { (QALYs) lost } \times \text { VLY }\end{array}$ & $\begin{array}{l}\text { For example, } \$ 8,147 \text { per rape incident } \\
\text { for the lost QOL (I } 989 \text { US\$) }\end{array}$ \\
\hline $\begin{array}{l}\text { Brand and Price (2000), England } \\
\text { and Wales, crime }\end{array}$ & $\begin{array}{l}\text { Cost estimates for pain and suffering based on QALYs technique } \\
\text { from another source }\end{array}$ & $\begin{array}{l}\ell \mid 7 b n \text { for crimes against individuals } \\
\text { and households }(1999 t)\end{array}$ \\
\hline
\end{tabular}

researchers make clear how they conceptualize the nature of costs, ideally by using the integrated framework presented in Table 1. Such a framework, which delineates costs according to different dimensions, can provide a more comprehensive understanding of the impact of the problem. Instead of arguing, for example, that "medical care for domestic violence comes with a certain price tag," using this framework would allow researchers to state that "a certain figure of long-term medical expenditure is mostly borne by the government as a consequence of domestic violence." This could be interpreted to mean that "the government has long been paying a high cost for reactive programs to domestic violence because it has not introduced adequate preventive measures."

\section{Inclusion of Cost Components}

To capture the full economic impact of domestic violence, researchers must incorporate all possible cost components into their studies, including those omitted from existing studies. Some cost components, such as second generation or informal support from family and friends, are omitted although they appear to be significant. For instance, some findings have suggested that a child's witnessing of domestic violence is associated with a greater propensity to commit juvenile and adult crime (Edleson, 1999; Tomison, 2000). This may mean increased costs for the criminal justice system and government services in the future. As it is possible that domestic violence and other forms of violence against children often occur together in households (Flood \& Fergus, 2008), it is difficult to separate the impact of these two intersecting forms of violence. Further research on the probability of committing juvenile and adult crime as a result of exposure to domestic violence would enable better estimation of intergenerational costs.

Measures of the long-term aspects of certain cost components, such as medical and mental health care, are also lacking in the literature. Evidence shows that domestic violence is a significant cause of disability among women in both the industrial and the developing worlds and that the psychological effects of violence are even more debilitating than the physical effects (Heise, Pitanguy, \& Germain, 1994). Female victims in the United States, for instance, are four to five times more likely than other women to require psychiatric treatment. A significant number of victims suffer from major depression and some go on to abuse alcohol or drugs (Heise et al., 1994). This evidence suggests the need for longer term medical and mental health treatment.

Additionally, more attention should be paid to costs, such as property damage and loss, organizational costs, loss of household economies of scale, loss of consumption efficiency in the households avoiding IPV by separation, government transfer costs, and human costs of family members and professionals handling IPV, which the studies addressed less frequently. The relative proportions of cost components to the total costs of domestic violence have been found to vary. Human costs form the largest proportion of total costs (Access Economics, 2004; Walby, 2004), while the next two largest are productivity losses and health care. These relative proportions reflect the relative 
degree of impact on different areas, and thus the reasons for interventions and how they should be prioritized. Those who are new to studying the costs of domestic violence could consider approaching the cost components in order of the size of their relative proportions to the total costs.

In calculating costs, it is also helpful to note both sides of the costs. For instance, the costs to employers from increased need of manpower to manage absenteeism might also be a benefit to the human resource staff. Bearing this in mind may prevent overstating total costs, such as those of lost productivity.

\section{Choosing the Right Data}

Calculating cost measures can be straightforward if pertinent data exist. However, given the lack of data in many circumstances, researchers must often settle for the best available data and use these as proxies for evidence (Yodanis et al., 2000). Many cost measures, particularly those based on unit service costs as found in medical care or mental health care, must rely heavily on estimated values from a range of other data sources. Therefore, researchers should be careful to choose the right data to obtain the most accurate estimates. Choosing data that are too old and nonrepresentative, for instance, will inevitably lead to inaccurate estimates.

\section{Constructing the Right Measures}

Cost measures can be constructed by adopting a bottom-up, top-down, or econometric approach - as seen from the costs on medical care and mental health care-according to the needs of the study and the limitations of the data. Because there is no evidence of bias or of a gold standard among them, they can be regarded as equally useful for making estimations. However, researchers must still take into account the potential limitations of each approach when designing cost measures. The bottom-up approach, which is largely based on unit cost estimates, could potentially lead to inaccurate results, if the estimates are derived from inappropriate sources. When adopting the top-down method to estimate medical costs, a confounding effect or effect modification could arise in the PAF formula (Brown et al., 2008). When estimating incremental costs using the econometric approach, the effect of confounding variables must be addressed (Brown et al., 2008).

Because the cost measures reviewed have come from studies of different countries, the measures from one country may not apply to another. Data availability and the institutional features of the health, social services, or legal systems determine how costs are measured. Therefore, researchers should use discretion when developing cost measures in a particular social context.

\section{Conclusion}

Cost studies have an essential role to play in moving toward evidence-based policy making because they can help integrate social issues into mainline policy discussion and decision making. This is not to say that cost analysis itself should be the sole decisive factor affecting policy decisions. However, political or partisan interests, among many other elements, can tend to be more influential forces. When those in power are made aware, however, that the hefty costs of a social problem going untreated are mostly borne by the public purse or by society as a whole, a more rational discussion is more likely to take place and multipartisan support achieved. In addition, cost studies have been successful in drawing attention and responses from the public as well as the policy-making and policy-influencing bodies.

Because the inconsistent findings of existing studies do not present a full enough picture for understanding or comparing the economic costs of domestic violence, we consider further discussion on how to improve cost studies beneficial. To provide a setting for that discussion, we have reviewed the different kinds of costs included in the existing literature and the ways they have been measured. We have further summarized these different kinds of costs in an integrated crosscategorization framework. Some of the ways in which these studies have measured costs include the bottom-up, topdown, and econometric approaches. We have discussed, based on our review, the importance of clearly defining the costs under study, capturing the full range of costs, choosing the right data, and constructing accurate measures and have suggested these as a guide for further dialogue and future study.

\section{Declaration of Conflicting Interests}

The author(s) declared no conflicts of interest with respect to the authorship and/or publication of this article.

\section{Funding}

The author(s) received no financial support for the research and/or authorship of this article.

\section{References}

Access Economics. (2004). The cost of domestic violence to the Australian economy: Part I. Canberra, Australia: Office of the Status of Women.

Arias, I., \& Corso, P. (2005). Average cost per person victimized by an intimate partner of the opposite gender: A comparison of men and women. Violence and Victims, 20, 379-391.

Brand, S., \& Price, R. (2000). The economic and social costs of crime. London, England: Home Office.

Brown, D. S., Finkelstein, E. A., \& Mercy, J. A. (2008). Methods for estimating medical expenditures attributable to intimate partner violence. Journal of Interpersonal Violence, 23, 1747-1766.

Clark, K. A., Biddle, A. K., \& Martin, S. L. (2002). A cost-benefit analysis of the Violence Against Women Act of 1994. Violence Against Women, 8, 417-428.

Cohen, M. A., \& Miller, T. R. (1998). The cost of mental health care for victims of crime. Journal of Interpersonal Violence, 13, 93-110.

Collins, D., \& Lapsley, H. (2003). The social costs and benefits of gambling: An introduction to the economic issues. Journal of Gambling Studies, 19, 123-148.

Edleson, J. L. (1999). The overlap between child maltreatment and woman battering. Violence Against Women, 5, 134-154. 
Flood, M., \& Fergus, L. (2008). An assault on our future: The impact of violence on young people and their relationships. Australia: The White Ribbon Foundation of Australia.

Greaves, L., Hankivsky, O., \& Kingston-Riechers, J. (1995). Selected estimates of the costs of violence against women. Ontario, Canada: Centre for Research on Violence Against Women and Children.

Haddix, A. C., Teutsch, S. M., \& Corso, P. S. (2003). Prevention effectiveness: A guide to decision analysis and economic evaluation (2nd ed.). New York, NY: Oxford University Press.

Heise, L. L., Pitanguy, J., \& Germain, A. (1994). Violence against women: The hidden health burden (World Bank Discussion Papers 255). Washington, DC: The World Bank.

Jones, A. S., Dienemann, J., Schollenberger, J., Kub, J., O'Campo, P., Gielen, A. C., \& Campbell, J. (2006). Long-term costs of intimate partner violence in a sample of female HMO enrollees. Women's Health Issues, 16, 252-261.

Krug, E. G., Dahlberg, L. L., Mercy, J. A., Zwi, A. B., \& Lozaro, R. (Eds.). (2002). World report on violence and health. Geneva, Switzerland: World Health Organization.

Miller, T. R., Cohen, M. A., \& Rossman, S. B. (1993). Victim costs of violent crime and resulting injuries. Health Affairs (Millwood), 12, 186-197.

Miller, T. R., Cohen, M. A., \& Wiersema, B. (1996). Victim costs and consequences: A new look. Washington, DC: National Institute of Justice.

Mugford, M., Hutton, G. F., \& Fox-Rushby, J. (1998). Methods for economic evaluation alongside a multicentre trial in developing countries: A case study from the WHO antenatal care randomised controlled trial. Paediatric \& Perinatal Epidemiology, 12, 75-97.

National Center for Injury Prevention and Control. (2003). Costs of intimate partner violence against women in the United States. Atlanta, GA: Centers for Disease Control and Prevention.

Reeves, C., \& O'Leary-Kelly, A. M. (2007). The effects and costs of intimate partner violence for work organizations. Journal of Interpersonal Violence, 22, 327-344.

Rossi, P. H, Freeman, H. E., \& Lipsey, M. W. (1999). Evaluation: A systematic approach (6th ed.). Thousand Oaks, CA: Sage.

Schwalberg, R., Gavin, N., \& Scarato, R. (1998). Economics in MCH. Rockville, MD: Health Resources \& Services Administration.

Teutsch, S. M. (1992). A framework for assessing the effectiveness of disease and injury prevention. MMWR Recommendations and Reports, 41, 1-12.
Tomison, A. M. (2000). Exploring family violence: Links between child maltreatment and domestic violence. Issues in Child Abuse Prevention, 13, 1-23.

Ulrich, Y. C., Cain, K. C., Sugg, N. K., Rivara, F. P., Rubanowice, D. M., \& Thompson, R. S. (2003). Medical care utilization patterns in women with diagnosed domestic violence. American Journal of Preventive Medicine, 24, 9-15.

Walby, S. (2004). The cost of domestic violence. London, England: Women and Equality Unit.

Waters, H., Hyder, A., \& Rajkotia, Y. (Eds.). (2004). The economic dimensions of interpersonal violence. Geneva, Switzerland: World Health Organization, Department of Injuries and Violence Prevention.

Weimer, D. L., \& Vining, A. R. (1999). Policy analysis: Concepts and practice (3rd ed.). Upper Saddle River, NJ: Prentice Hall.

Wisner, C. L., Gilmer, T. P., Saltzman, L. E., \& Zink, T. M. (1999). Intimate partner violence against women: Do victims cost health plans more? The Journal of Family Practice, 48, 439-443.

Yodanis, C. L., Godenzi, A., \& Stanko, E. A. (2000). The benefits of studying costs: A review and agenda for studies on the economic costs of violence against women. Policy Studies, 21, 263-276.

\section{Bios}

Ko Ling Chan, $\mathrm{PhD}$, is an assistant professor of social work at the University of Hong Kong. He has established his expertise in the area of family violence and has conducted researches including the impact of family violence on battered women and their children; narrative accounts of male batterers; pregnancy and violence; international dating violence study, and so on. He had completed a research project commissioned by the Hong Kong Government to study the prevalence rates and the risk factors of spousal and child abuse in Hong Kong, to review the legislative measures, and to validate the risk assessment tool. He has developed an indigenous model of explaining Chinese men who batter their wives. The model uses Chinese concepts of face to explain the development of Chinese masculinity. He is directing a study of domestic violence costs and a study of child sexual abuse in China.

Esther Yin-Nei Cho, $\mathrm{PhD}$, is a lecturer of social work at the Hong Kong Baptist University. Her areas of research are human capital and asset development of women and children. She is a member in a study of child sexual abuse in China. 